\title{
28 Research Soure \\ Therapeutic Efficacy of Entecavir and Tenofovir among the Affectees from War against Terror in the Tribal Areas of Pakistan
}

\author{
Asim Jan \\ Abasyn University \\ Hayat Khan \\ University of Swabi \\ Majeed Ur Rehman \\ Abasyn University \\ Muhammad Salman \\ Abasyn University \\ ljaz Ali \\ COMSATS University Islamabad \\ Jadoon Khan \\ Abasyn University

\section{Abid Sarwar} \\ University of Swabi \\ Latifur Rehman ( $\nabla$ latifurrehman@uoswabi.edu.pk) \\ University of Swabi
}

\section{Research}

Keywords: Hepatitis B infection, Tribal belt, Entecavir, Tenofovir Disoproxil Fumarate

Posted Date: December 30th, 2021

DOI: https://doi.org/10.21203/rs.3.rs-1115955/v1

License: (c) (i) This work is licensed under a Creative Commons Attribution 4.0 International License. Read Full License 


\section{Abstract}

\section{Background}

Hepatitis B infection is a worldwide health concern infecting more than 400 million people worldwide. Besides the active immunization program of $\mathrm{WHO}$, the role of antivirals for treating the chronic infection is inevitable. The tribal belt of Pakistan is the most affected part in war against terror. In addition to lack of basic facilities and resources, this part of country has also been neglected for various health related studies. In this study we report the efficacy of the commonly used antivirals; Entecavir (ETV) and Tenofovir Disoproxil Fumarate (TDF).

\section{Methods}

A total of 2875 HBV infected patients (Male $=1500$ and Female $=1375$ ) of different age groups who were receiving either ETV as monotherapy or ETV plus TDF were followed up for 6 and 12 months. Viral DNA was extracted from serum followed by amplification and detection with MyGo Real-Time thermocycler and Gene Proof PCR kit. Response towards antivirals was analyzed statistically with Pearson's Chi Square test.

\section{Results}

Comparable response $(p=0.171)$ was observed among the HBV patients towards both six $(27 \%)$ and twelve month antiviral therapy (36\%). Duration of antiviral therapy improved the rate of response in male and patients of old age ( $p=0.001 \&<0.001$ respectively). However, female were found relatively more responsive than males towards both six and twelve antiviral therapy ( $p=0.001 \& 0.003$ respectively). Furthermore, ETV plus TDF combination proved little more effective for twelve months $(p=0.035)$. Patients of Khyber $(p=0.198)$ and Kurrum $(p=0.440)$ regions are equally responsive towards 6 and 12 month treatment. Compared to ETV monotherapy, ETV plus TDF improved response among the male, patients above 40 years and patients from different tribal region (Bajaur, Kurrum, Malakand and Mohmand).

\section{Conclusion}

Our findings demonstrate that the ETV monotherapy and ETV plus TDF combination therapy are not effective for the HBV infection because both do not achieve SVR rate even in $50 \%$ of patients following six and twelve-month follow-up. Therefore, there is a need of much more effective antiviral drugs to treat HBV infection in the study area.

\section{Background}

Globally around 400 million people are living with HBV infection, out of which $15-40 \%$ progress to end stage liver diseases of uncompensated cirrhosis and hepatocellular carcinoma (HCC). About $45 \%$ of world population are living in areas where there is a high incidence of HBV carrier infection. The Western pacific and Asia accounts for $75 \%$ of the whole population living in HBV prevalent areas [1]. The exact percent prevalence of HBV in Pakistan is obscured however, some says that 10 million Pakistanis are suffering from the HBV [2].

Hepatitis B is an enveloped and partially double stranded DNA virus that can transmit through blood, semen, saliva, menstrual blood, vaginal secretions, and similarly slightly through, tears, breast milk, urine, and perspiration of infected persons [3-5]. The genome is $3.2 \mathrm{~kb}$ long containing 4 open reading frames (ORFs), the surface (S), the core $(C)$, Polymerase $(P)$, and the $X$ gene. Several genotypes and subtypes have been reported for the HBV owing to 
its genetic heterogeneity [6]. Lack of proofreading associated with viral reverse transcriptase (RT) and phenomenon of genetic recombination are the main reasons for the genetic heterogeneity of HBV genome [7-9].

Prophylaxis in the form of vaccine is available for the prevention of HBV since 1981 [10]. The WHO has initiated the Hepatitis B vaccination program for the children across almost across the world. According to a report in $2003,79 \%$ children had received the vaccination for the hepatitis $B$ [11]. In order to reduce the risk of cirrhosis and hepatocellular carcinoma, the chronic HBV patients are being treated with various regimes of available antivirals and interferon. The current treatment of chronic HBV infection involves lamivudine (3TC), entecavir (ETV), adefovir (ADV), tenofovir (TDF), telbivudine (LdT), and pegylated interferon- $a 2 a, 2 b$ [12]. The available therapeutic regime have low level of resistance barrier because these are nucleoside analogues to which HBV can readily develop resistance as it lacks the proofreading activity.

The present study was designed to assess the efficacy of two widely used antivirals; entecavir (ETV) and tenofovir (TDF) in the tribal territory of Pakistan officially known as Federally Administered Tribal Area (FATA). This area has been neglected to study the therapeutic outcomes of antivirals because of very poor socio-economic condition and great losses from war against terror.

\section{Methods}

The current study was carried out in the Abaseen Research and Reference Laboratory (ARRL), Peshawar from September, 2016 to June, 2018. A total of 2875 HBV infected patients (Male $=1500$ and Female $=1375)$ of different age groups who were receiving antiviral therapy of Entecavir (ETV) and Tenofovir Disoproxil Fumarate (TDF) both as Mono or Combination therapy for six and twelve months were included in the study. Patients who were not responding to the therapy at the end of six months continued the treatment for another six months. The study was approved by ethical committee of Abasyn University Peshawar as well as informed consents were also signed from the patients or their guardian during the sampling. Blood samples were collected from the patients either visiting directly to the ARRL or via its coordinate collection points in the study area. All the relevant information were also recorded on a pre-designed proforma.

\section{Extraction Of Viral DNA}

Following sample collection in the gel tube, blood serum was separated by centrifugation at 8000 rpm for 5 minutes. Serum was then collected in $2.0 \mathrm{ml}$ tubes and were either processed for the HBV DNA extraction or stored at $-20^{\circ} \mathrm{C}$ for further use. For HBV DNA extraction NucleoSpin ${ }^{\circledR}$ virus kit was used according to the manufacturer's protocols in the type IIB biosafety hood.

\section{Quantification Of Viral DNA}

Viral DNA was quantified with the help of MyGo Real-Time thermocycler and Gene Proof PCR kit (Ready to use Master Mix). Briefly, 30 $\mu$ l of Master Mix is mixed with $10 \mu \mathrm{l}$ of HBV DNA in $0.2 \mathrm{ml} \mathrm{PCR}$ tubes. For quantification of viral DNA and determination of accuracy of assay, standard and control reactions were also carried out. Following mixing of Master Mix and HBV DNA, tubes were spinned shortly and then incubated at room temperature for 5 min according to the manufacturer protocol. After incubation the tubes were placed in the blocks of thermocycler and caps of the tubes were ensured to close properly. Different rows of wells containing samples, standards and 
controls were properly labelled using MyGo real-time PCR software so that it can be easily identified after the run. Two different fluorescent dye detectors were selected i.e. FAM (blue) and HEX (green) detectors. The FAM dye in the Master Mix is used for the detection of HBV DNA in the sample whereas HEX dye is used for the internal standard. The results were analyzed after the run by adjusting the $\mathrm{Ct}$ (Threshold cycle) value that exceed the background fluorescence or signal.

\section{Statistical Analysis}

The responders and non-responders were analyzed statistically for significance in association with various factors such as gender, age, area, types and duration of treatment. Pearson Chi square test was used for the calculation of p with SPSS.

\section{Results}

The present study was carried out to assess the therapeutic outcomes of commonly used antivirals; Entecavir (ETV) and Tenofovir Disoproxil Fumarate (TDF), against the HBV infection in tribal area of Pakistan suffered from war against terror. The efficacy of antivirals was evaluated for the six and twelve-month therapeutic regime. Overall the rate of response was relatively high for twelve months of treatment as compared to six months (Table 1). However, the difference is non-significant with a $p$ value of 0.171 which is higher than 0.5 . Furthermore, the response was evaluated with respect to different parameters such as gender, age, type of therapy and area and it was found that females were relatively more responsive towards the six months treatment whereas the gender proved to have no effect on the rate of response for the twelve months antiviral regime (Tables $2 \& 3$ ). Similarly, combination therapy proved relatively more effective for the 12 months than 6 months as compared to monotherapy where no significant difference was observed between the 6 and 12 months response towards the monotherapy (Table 2). Twelve months treatment was highly effective in patients over 40 years (Table 2) whereas age groups below 40 years show comparable response towards both 6 and 12 months treatment (Table 2). Among the patients of different tribal regions, the response rate was considerably high among the patients from Khyber and Waziristan agencies whereas very low response was observed among the HBV infected patient of Orakzai agency both for the six and twelve month duration of treatments (Table 2). Moreover, efficacy of antiviral treatment was comparatively higher in patients from Orakzai, Malakand, Mohmand, Bajour and Waziristan agencies following 12 months treatment (Table 2). The effect of monotherapy and combination therapy was also assessed in relation to various parameters and it was found that combination therapy either does not or slightly improve the response among various groups following both six and twelve month therapy (Tables 3 \& 4).

Table 1

Frequency of responders and non-responders following $6 \& 12$ antiviral treatment for HBV patients

\begin{tabular}{|llll|}
\hline & Responder & Non-responder & $p$ Value \\
\hline Six Months & $27 \%$ & $73 \%$ & \\
\hline Twelve Months & $36 \%$ & $64 \%$ & 0.171 \\
\hline $\begin{array}{l}p \text { Value obtained from } \\
\text { therapeutic response. }\end{array}$ & & & \\
\hline
\end{tabular}


Table 2

Frequency of 6 \& 12 months' responders and non-responders among the different genders, age groups and patients of various regions receiving different therapy

\begin{tabular}{|llll|}
\hline & Six Months Responders & Twelve Months Responders & $p$ Value \\
\hline Male & $265(17.67 \%)$ & $345(38.86 \%)$ & 0.001 \\
\hline Female & $510(37.10 \%)$ & $280(32.37 \%)$ & 0.328 \\
\hline Monotherapy & $325(28.01 \%)$ & $270(32.3 \%)$ & 0.270 \\
\hline Combination Therapy & $450(26.23 \%)$ & $490(38.73 \%)$ & 0.035 \\
\hline Age Group: $11-25$ & $46(33.22 \%)$ & $305(32.9 \%)$ & 0.560 \\
\hline Age Group: $26-40$ & $280(27.45 \%)$ & $285(38.5 \%)$ & 0.065 \\
\hline Age Group: $40 \infty$ & $35(7.44 \%)$ & $170(39.0 \%)$ & 0.001 \\
\hline Orakzai & $50(10.42 \%)$ & $15(3.4 \%)$ & 0.004 \\
\hline Bajour & $110(27.5 \%)$ & $135(46.5 \%)$ & 0.198 \\
\hline Khyber & $185(46.25 \%)$ & $115(53.4 \%)$ & 0.440 \\
\hline Kurrum & $175(33.33 \%)$ & $110(31.4 \%)$ & $<0.001$ \\
\hline Malakand & $25(7.70 \%)$ & $150(50 \%)$ & 0.009 \\
\hline Mohmand & $70(20 \%)$ & $100(35.7 \%)$ & 0.012 \\
\hline Waziristan & $160(40.50 \%)$ & $135(57.4 \%)$ & 0.041 \\
\hline
\end{tabular}


Table 3

Therapeutic outcomes of 6 months' monotherapy and combination among the different genders, age groups and patients of various regions

\begin{tabular}{|c|c|c|c|c|c|c|}
\hline & \multicolumn{2}{|c|}{ Monotherapy (Six Months) } & \multirow[t]{2}{*}{$P_{\text {Value }}$} & \multicolumn{2}{|c|}{$\begin{array}{l}\text { Combination Therapy (Six } \\
\text { Months) }\end{array}$} & \multirow[t]{2}{*}{$\stackrel{p}{\text { Value }}$} \\
\hline & Responder & $\begin{array}{l}\text { Non- } \\
\text { Responder }\end{array}$ & & Responder & Non-Responder & \\
\hline Male & $130(18.80 \%)$ & $560(81.20 \%)$ & & $135(16.60 \%)$ & $675(83.40 \%)$ & \\
\hline Female & $195(41.40 \%)$ & $275(58.60 \%)$ & 0.001 & $315(34.80 \%)$ & $590(65.20 \%)$ & 0.003 \\
\hline Age Group: 11-25 & $175(27.34 \%)$ & $195(72.66 \%)$ & & $285(38.26 \%)$ & $460(61.74 \%)$ & 0.065 \\
\hline Age Group: 26-40 & $150(33.70 \%)$ & $295(66.30 \%)$ & & $130(22.60 \%)$ & $445(77.40 \%)$ & 0.058 \\
\hline $\begin{array}{l}\text { Age Group: Above } \\
40\end{array}$ & $0(0 \%)$ & 75 (100\%) & & $35(8.9 \%)$ & $360(91.1 \%)$ & 0.002 \\
\hline Orakzai & $15(6.25 \%)$ & $225(93.75 \%)$ & & $35(14.58 \%)$ & $204(85.42 \%)$ & 0.031 \\
\hline Bajour & $55(55 \%)$ & $45(45 \%)$ & & $55(18.33 \%)$ & $245(81.67 \%)$ & $<0.001$ \\
\hline Khyber & $110(50 \%)$ & $110(50 \%)$ & & $75(41.66 \%)$ & $105(58.34 \%)$ & 0.160 \\
\hline Kurrum & $105(38.1 \%)$ & $170(61.9 \%)$ & & $70(28 \%)$ & $180(72 \%)$ & 0.088 \\
\hline Malakand & $10(6.10 \%)$ & $155(93.9 \%)$ & & $15(9.38 \%)$ & $145(90.62 \%)$ & 0.296 \\
\hline Mohmand & $0(0 \%)$ & $50(100 \%)$ & & $70(23.3 \%)$ & $230(76.7 \%)$ & $<0.001$ \\
\hline Waziristan & 30 (27.27\%) & $80(72.73 \%)$ & & $130(45.61 \%)$ & 155 (54.39\%) & 0.004 \\
\hline
\end{tabular}


Table 4

Therapeutic outcomes of 6 months' monotherapy and combination among the different genders, age groups and patients of various regions

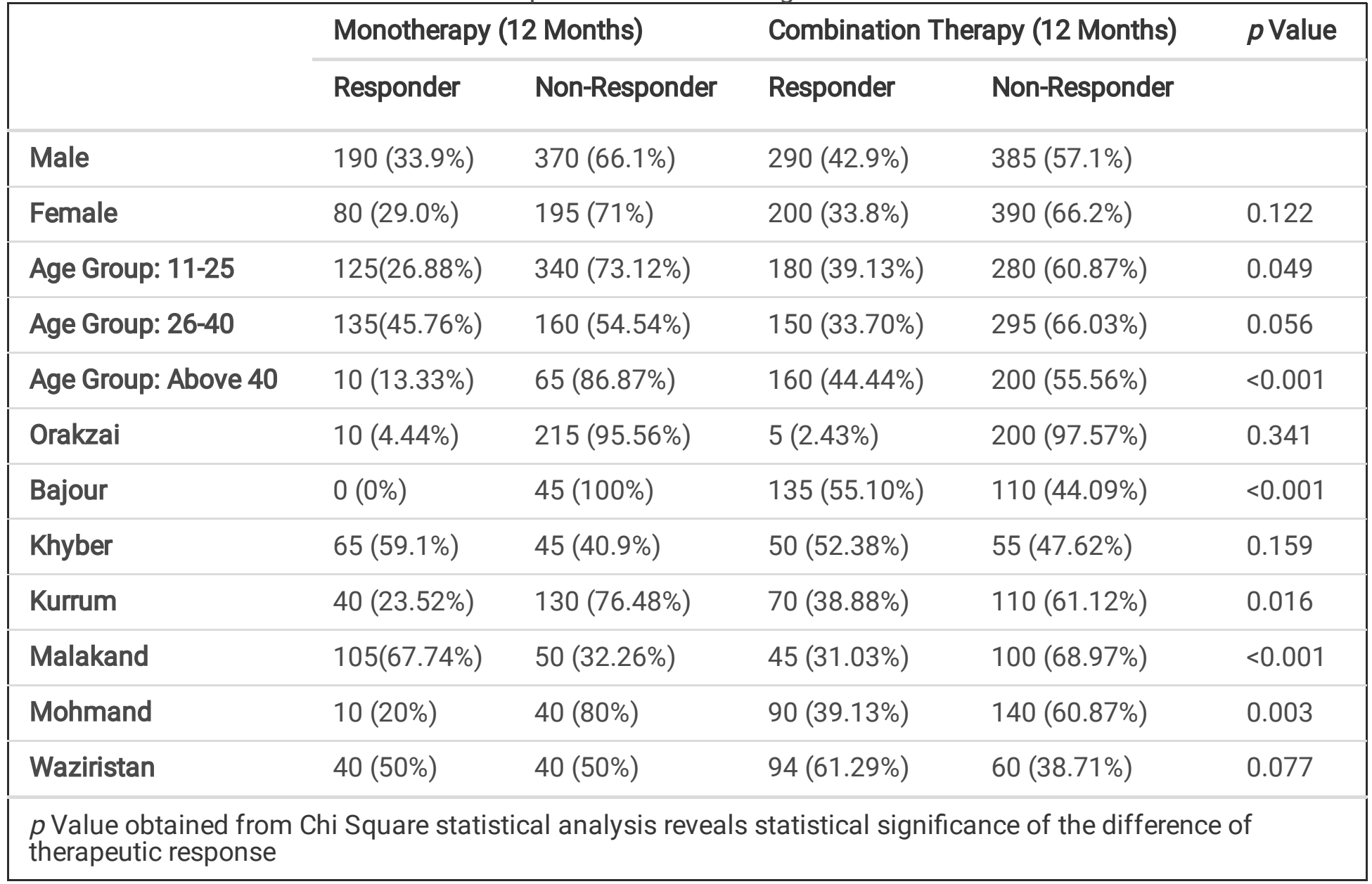

\section{Discussion}

Worldwide about 400 million human beings are infected by HBV causing severe liver complications, as well as decompensated cirrhosis and HCC [4]. The global population of about $45 \%$ live in areas that have high incidence of chronic HBV infections in which chronic carriers of about $75 \%$ live in the Western Pacific and Asia. Around 15-40\% of HBV infection progress to liver cirrhosis, fibrosis and HCC, and 0.5-1.2 million HBV patients pass the infection per year. Because of the high HBV-related mortality and morbidity, the Hepatitis B worldwide disease burden is significant [13]. The exact incidence of HBV is yet obscure in Pakistan however at least 10 million peoples are probably supposed to be infected with chronic Hepatitis B (CHB) infection [2].

In this study we have investigated the efficacy of entecavir (ETV) monotherapy and entecavir plus Tenofovir Disoproxil Fumarate (TDF) combination therapy in HBV infected patients in the war affected tribal belt of Pakistan. The therapeutic outcomes of these antivirals were also correlated with various factors such as age group, gender, and various demographic regions of tribal belt following six and twelve month's treatment. Overall, the response rate was a little higher for the 12 months with $27 \%$ and $36 \%$ of patients showed sustained virologic response (SVR) respectively for 6 and 12 months of antiviral treatment. Previously, it has been observed that ETV does not affect significantly the HBV viral load after three months treatment, however, it inhibits HBV completely in $54 \%$ of patients following six months' therapy [14]. Another study reports SVR in $43 \%$ of patients following six months treatment [15]. When various factors such as gender, age and geographic regions were assessed for their influence upon the 
SVR of antivirals following six and twelve month treatment, it was observed that males are relatively more responsive towards twelve month antiviral therapy but showed significantly low level of response as compared to the female at end of six month treatment. Duration of treatment had no effect on the SVR among the female. Male relatively proved less responsive towards both ETV monotherapy and combination therapy of ETV and TDF for six month duration, however, comparable rate of response was observed among the both gender for the twelve month treatment of ETV alone or ETV plus TDF. Earlier studies have also highlighted the effect of gender on disease progression and treatment response among the different genders of HBV patients. One study reported that HBV infection progresses relatively more rapid in men than women and the women show better response towards the HBV therapy because it might be the intervening of sexual hormone with the viral replication and estrogen mediated boosting of immune responses towards HBV [16]. The gender based differential response might be explained by the mechanism of adherence and non-adherence of drug. The ETV and TDF might require more time to adhere in the male than female and because of this female exhibit more response towards the therapy for six months whereas a relatively improved response will be observed in male than female following twelve-month treatment [17].

Similarly, ETV monotherapy had comparable efficacy both for the 6 and 12 month treatment but improved significantly at the end of 12 months for the combination therapy of ETV plus TDF. Previous reports demonstrate contradictory findings about the therapeutic outcomes of monotherapy and combination therapy in association with different duration of antiviral therapy. Comparable potency of ETV monotherapy and ETV plus TDF combination therapy has also been observed earlier [18]. Besides similar potency of monotherapy and combination, similar therapeutic outcomes were also observed in the same report following six and twelve-month therapy (Anna et al., 2012). Furthermore, a much higher potency has also been reported for the combination therapy of ETV and TDF with SVR achieved in $97 \%$ and $83 \%$ of HBV respectively following six and twelve-month therapy [19].

Correlation of age factor and antiviral efficacy was also explored in HBV patients. Patients below 40 years did not show any significant difference in SVR both for the six and twelve month antiviral therapy, however, the rate of SVR has improved significantly in patient who were above 40 years after twelve months treatment as compared to six month therapy. Furthermore, antiviral therapy of ETV plus TDF for twelve month proved relatively more effective in patient of younger and older age. Previously patients above 40 years have shown higher response towards combination therapy of ETV and ADV/LAM than monotherapy of ETV or ADV [20]. However, the response of LAM and ETV was much higher in patients of young age. Immunity is the main reason for the good response among the patients of young age towards the antivirals [21] because HBV clearance has been observed in about $90 \%$ of infected adults which is a strong evidence for the role of immunity in young people [22].

In the current study response rate of the HBV patients was also assessed among the various tribal regions and it was found that patients from Khyber and Waziristan agencies show relatively good response towards the antiviral therapy following six-month treatment. Monotherapy and combination therapy has differential findings at the end of six month among the patients of various tribal regions. Monotherapy is comparatively more effective among the patients of Bajour and Kurrum regions whereas patients from rest of the regions show improvement in SVR following six months treatment. Following twelve month treatment duration the combination therapy proved very effective among the patients of different regions except Malakand. Earlier studies also show geographic effect on therapeutic outcomes of antiviral against the HBV the infection that might be because of different HBV genotypes circulating in different demographic regions. Differential response of ETV/LAM and ETV plus TDF was observed in HBV patients from Turkey (41.2\%), Denmark (9.7\%), Austria (28.3\%), and Italy 20.8\% following 12-months therapy 
[23]. The genotype specific response of HBV towards nucleoside analogue and interferons has also been studied in different geographic areas of Japan and it was found that genotypes $C$ and $D$ was relatively low responsive than genotype A and B [24].

\section{Conclusion}

In short, the findings of the current study demonstrate that ETV monotherapy and ETV plus TDF combination therapy are not effective for the HBV infection because both do not achieve SVR rate even in $50 \%$ of patients following six and twelve-month follow-up. Gender factor seems to affect the response towards the antiviral therapy at the end of months but has no affect following 12 month treatment. Age factor seems to affect the efficacy because the patients under 40 year show comparatively good response towards the therapy than the patients above 40. Combination therapy of ETV plus TDF improve little the SVR for twelve months duration against the six months duration.

\section{Declarations}

\section{Ethics approval and consent to participate}

The study was approved from the Ethical committee of the Abasyn University Peshawar. Informed consents were asked from patients at the time of sampling.

\section{Consent for publication}

N/A

\section{Availability of data and materials}

N/A

\section{Competing interests}

The authors declare that they have no competing interests

\section{Funding}

N/A

\section{Authors' contributions}

HK and IA designed the study. AJ, MR, MS and JK collected samples and carried out experimental work. AS, HK and LR prepared and reviewed the manuscript.

\section{Acknowledgements}

N/A

\section{Referefnes}


1. Balabanova Y, Gilsdorf A, Buda S, Burger R, Eckmanns T, Gärtner B, et al. Communicable Diseases Prioritized for Surveillance and Epidemiological Research: Results of a Standardized Prioritization Procedure in Germany, 2011. Mokrousov I, editor. PLoS One [Internet]. Public Library of Science; 2011;6:e25691-e25691. Available from: https://doi.org/10.1371/journal.pone.0025691

2. Qureshi H, Bile KM, Jooma R, Alam SE, Afrid HUR. Prevalence of hepatitis B and C viral infections in Pakistan: findings of a national survey appealing for effective prevention and control measures. Eastern Mediterranean Health Journal [Internet]. 2010;16:15-23. Available from: http://applications.emro.who.int/emhj/V16/supp/16_S_2010_015_023.pdf

3. Al-Busafi SA, Al-Harthi R, Al-Naamani K, Al-Zuhaibi H, Priest P. Risk Factors for Hepatitis B Virus Transmission $\otimes$ in Oman. Oman Med J [Internet]. OMJ; 2021;36:e287-e287. Available from: https://pubmed.ncbi.nlm.nih.gov/34405055

4. Asli M, Kandelouei T, Rahimyan K, Davoodbeglou F, Vaezjalali M. Characterization of Occult Hepatitis B Infection Among Injecting Drug Users in Tehran, Iran. Hepat Mon [Internet]. 2016;16:1-15. Available from: https://sites.kowsarpub.com/hepatmon/articles/15602.html

5. Davis LG, Weber DJ, Lemon SM. Horizontal transmission of hepatitis B virus. Lancet (London, England). 1989;1:889-93.

6. Kramvis A. Genotypes and Genetic Variability of Hepatitis B Virus. Intervirology [Internet]. 2014;57:141-50. Available from: https://www.karger.com/DOI/10.1159/000360947

7. Duffy S, Shackelton LA, Holmes EC. Rates of evolutionary change in viruses: patterns and determinants. Nature Reviews Genetics [Internet]. Nature Publishing Group; 2008;9:267-76. Available from: https://doi.org/10.1038/nrg2323

8. Nasu A, Marusawa H, Ueda Y, Nishijima N, Takahashi K, Osaki Y, et al. Genetic Heterogeneity of Hepatitis C Virus in Association with Antiviral Therapy Determined by Ultra-Deep Sequencing. Yamaoka Y, editor. PLoS One [Internet]. Public Library of Science; 2011;6:e24907-e24907. Available from: https://doi.org/10.1371/journal.pone.0024907

9. Shi W, Zhu C, Zheng W, Zheng W, Ling C, Carr MJ, et al. Subgenotyping of Genotype C Hepatitis B Virus: Correcting Misclassifications and Identifying a Novel Subgenotype. Qiu J, editor. PLoS One [Internet]. Public Library of Science; 2012;7:e47271-e47271. Available from: https://doi.org/10.1371/journal.pone.0047271

10. Chang M-H, Chen D-S. Prevention of hepatitis B. Cold Spring Harb Perspect Med [Internet]. Cold Spring Harbor Laboratory Press; 2015;5:a021493-a021493. Available from: https://pubmed.ncbi.nlm.nih.gov/25732034

11. Goldstein ST, Zhou F, Hadler SC, Bell BP, Mast EE, Margolis HS. A mathematical model to estimate global hepatitis B disease burden and vaccination impact. Int J Epidemiol [Internet]. 2005;34:1329-39. Available from: https://doi.org/10.1093/ije/dyi206

12. De Clercq E, Férir G, Kaptein S, Neyts J. Antiviral treatment of chronic hepatitis B virus (HBV) infections. Viruses [Internet]. 2010/05/31 ed. Molecular Diversity Preservation International (MDPI); 2010;2:1279-305. Available from: https://pubmed.ncbi.nlm.nih.gov/21994680

13. Lok ASF, McMahon BJ, Brown RS, Wong JB, Ahmed AT, Farah W, et al. Antiviral therapy for chronic hepatitis B viral infection in adults: A systematic review and meta-analysis. Hepatology [Internet]. 2016;63:284-306. Available from: https://onlinelibrary.wiley.com/doi/10.1002/hep.28280

14. Chang T-T, Lai C-L, Kew Yoon S, Lee SS, Coelho HSM, Carrilho FJ, et al. Entecavir treatment for up to 5 years in patients with hepatitis B e antigen-positive chronic hepatitis B. Hepatology [Internet]. Elsevier Ltd; 
2010;51:422-30. Available from: http://dx.doi.org/10.1016/S0739-5930(10)79545-3

15. Yuen M-F, Seto W-K, Fung J, Wong DK-H, Yuen JC-H, Lai C-L. Three Years of Continuous Entecavir Therapy in Treatment-Naïve Chronic Hepatitis B Patients: VIRAL Suppression, Viral Resistance, and Clinical Safety. Am J Gastroenterol [Internet]. 2011;106:1264-71. Available from:

https://journals.Iww.com/ajg/Fulltext/2011/07000/Three_Years_of_Continuous_Entecavir_Therapy_in.15.aspx

16. Wang S-H, Chen P-J, Yeh S-H. Gender disparity in chronic hepatitis B: Mechanisms of sex hormones. J Gastroenterol Hepatol [Internet]. John Wiley \& Sons, Ltd (10.1111); 2015;30:1237-45. Available from: https://doi.org/10.1111/jgh.12934

17. Hongthanakorn C, Chotiyaputta W, Oberhelman K, Fontana RJ, Marrero JA, Licari T, et al. Virological breakthrough and resistance in patients with chronic hepatitis $B$ receiving nucleos(t)ide analogues in clinical practice. Hepatology. John Wiley \& Sons, Ltd; 2011;53:1854-63.

18. Lok ASF, Ward JW, Perrillo RP, McMahon BJ, Liang TJ. Reactivation of Hepatitis B During Immunosuppressive Therapy: Potentially Fatal Yet Preventable. Ann Intern Med [Internet]. 2012;156:743-5. Available from: http://annals.org/article.aspx?doi=10.7326/0003-4819-156-10-201205150-00013

19. Yip B, Ha NB, Kim LH, Ahmed A, Ayoub W, Cooper AD, et al. Ethnic Differences in Clinical Characteristics and Treatments of Asian and Non-Asian With Hepatitis C (HCV)-Related Hepatocellular Carcinoma (HCC). Gastroenterology [Internet]. AGA; 2012;142:S-915. Available from: http://dx.doi.org/10.1016/S00165085(12)63551-3

20. Zhang Q, Han T, Nie C-Y, Ha F-S, Liu L, Liu H. Tenofovir rescue regimen following prior suboptimal response to entecavir and adefovir combination therapy in chronic hepatitis B patients exposed to multiple treatment failures. J Med Virol [Internet]. John Wiley \& Sons, Ltd; 2015;87:1013-21. Available from: https://doi.org/10.1002/jmv.24153

21. Spradling PR, Xing J, Williams R, Masunu-Faleafaga Y, Dulski T, Mahamud A, et al. Immunity to Hepatitis B Virus (HBV) Infection Two Decades after Implementation of Universal Infant HBV Vaccination: Association of Detectable Residual Antibodies and Response to a Single HBV Challenge Dose. Clinical and Vaccine Immunology [Internet]. American Society for Microbiology; 2013;20:559-61. Available from: https://www.ncbi.nlm.nih.gov/pubmed/23408522

22. Liang TJ. Hepatitis B: The virus and disease. Hepatology [Internet]. John Wiley \& Sons, Ltd; 2009;49:S13-S21. Available from: https://doi.org/10.1002/hep.22881

23. Hermans LE, Svicher V, Pas SD, Salpini R, Alvarez M, Ben Ari Z, et al. Combined Analysis of the Prevalence of Drug-Resistant Hepatitis B Virus in Antiviral Therapy-Experienced Patients in Europe (CAPRE). J Infect Dis [Internet]. 2016;213:39-48. Available from: https://academic.oup.com/jid/articlelookup/doi/10.1093/infdis/jiv363

24. Janssen HLA, van Zonneveld M, Senturk H, Zeuzem S, Akarca US, Cakaloglu Y, et al. Pegylated interferon alfa$2 \mathrm{~b}$ alone or in combination with lamivudine for HBeAg-positive chronic hepatitis B: a randomised trial. Lancet [Internet]. Elsevier; 2005;365:123-9. Available from: https://doi.org/10.1016/S0140-6736(05)17701-0 